\title{
Experimental analysis of the effect of electrokinetic treatment of soils
}

\author{
Sara Gargano $^{1 *}$, Stefania Lirer $^{2}$, Barbara Liguori $^{3}$, and Alessandro Flora ${ }^{1}$ \\ ${ }^{1}$ University of Napoli Federico II, Department of Civil, Architectural and Environmental Engineering (DICEA), Italy \\ ${ }^{2}$ University Guglielmo Marconi (Rome), Department of Sustainability Engineering (DIS), Italy \\ ${ }^{3}$ University of Napoli Federico II, Department of Chemical, Materials and Industrial Production Engineering (DICMaPI), Italy
}

\begin{abstract}
In Europe, large amounts of materials are dredged annually to maintain channels and harbour activities. Consolidation processes in dredged sediments take very long-time due to the high-water content, much more than those considered in the typical problems of geotechnical engineering. The electrokinetic treatment (EK) can be an effective technique to accelerate the dewatering of these sediments and, at the same time, to improve their mechanical properties. An experimental research is under course at the University of Napoli Federico II with the aim to analyse the effects induced by EK treatments on the physic-chemical and mechanical properties of two different soils. Some laboratory tests have been carried out in a special apparatus (special oedometer) adopting two different pore fluids (tap water and sea water). The laboratory results show that the effect of EK treatment, both in terms of induced water flow and improvement of soil mechanical properties, is affected by the chemical properties of the pore fluid and by the physical and mineralogical characteristics of the particles. The results obtained at the macro-scale (specimen) have been analysed at the micro-scale by means of X-ray diffraction analysis and Scanning Electron Microscopy, comparing the microstructures of treated and untreated soils specimens.
\end{abstract}

\section{Introduction}

Maritime transportation is more and more relevant in the world's economy. The need to offer access and handling of last generation ships $(8,000$ or more TEUs) has resulted, in the recent years, in the increase of dredging activities in many countries in the world, with huge volumes of sediments to be disposed.

The new European Union directives (OSPAR Convention, 1992) encourage to find environmentally sound solutions for the management of dredged soils.

Several opportunities for the beneficial uses of dredged materials have been identified, among them: construction fill (highway, road, airport), marine projects (construction of artificial islands, sediment tanks, beach nourishment, coastal defence structures) and manufacturing building materials (bricks, lightweight aggregate or cement filler).

It is well known that dredged sediments are underconsolidated soils, with an extremely high water content, sometimes contaminated, therefore, their possible reuse in civil fields needs treatments as dewatering, decontamination and stabilization. Dewatering is a key process because of the need to reduce the volume of the dredged sediments and to improve their mechanical soils properties.

Electrokinetic (EK) treatments represent a very effective technique for inducing a water flow without imposing hydraulic gradients in low permeability soils ([1]): in this case, the water flow is activated when the soil volume is charged with low voltage direct current via electrodes (cathode and anode) placed into the ground. The applied electrical potential difference induces ions migration within the fluid phase: the positively charged ionic species move through the medium to the cathode (negative pole), while the negatively ones move to the anode (positive pole). As the ions migrate, they drag their hydration water and cause a viscous drag of the water around them (electro-osmosis). The water flow is initiated in the diffuse double layer, where there are significantly more cations than anions due to the proximity of the negatively charged surface of clayey particles.

The application of an electric gradient in a soil volume induces a water flow that can be related to the applied voltage $\Delta \Phi$ with a flow rule similar to the one caused by a hydraulic gradient (Darcy's equation). The form of such an equation is:

$$
q_{e}=k_{e} i_{e} A_{c}
$$

in which $\mathrm{i}_{\mathrm{e}}$ is the electrical potential gradient $(\mathrm{V} / \mathrm{m}), \mathrm{k}_{\mathrm{e}}$ is the electro-osmotic permeability $\left(\mathrm{m}^{2} / \mathrm{sV}\right)$ and $\mathrm{A}_{\mathrm{c}}$ the area of the cross section $\left(\mathrm{m}^{2}\right)$. The electrical potential gradient $i_{\mathrm{e}}$ is defined as:

* Corresponding author: sara.gargano@unina.it 


$$
i_{e}=\frac{\Delta \Phi}{\Delta L}
$$

where $\Delta \phi$ is the applied potential difference $(\mathrm{V})$ and $\Delta \mathrm{L}$ is the distance between the electrodes.

The electro-osmotic permeability $\mathrm{k}_{\mathrm{e}}$ quantifies the pore flow rate in response to the applied voltage gradient. One of the constitutive relationships for the electro-osmotic permeability is that one proposed by Mitchell and Soga ([2]):

$$
k_{e}=\frac{\zeta s}{\eta} \cdot \frac{e}{1+\theta}
$$

in which $\zeta(\mathrm{V})$ is the so called "soil zeta potential"; $\varepsilon$ $(\mathrm{F} / \mathrm{m})$ is the dielectric constant of the pore fluid; $\eta(\mathrm{Pa} \mathrm{s})$ the dynamic viscosity of the fluid; e the void ratio of the soil.

Therefore, the water flow induced by the electric field (eq. 1) is governed by the mineralogical composition of the particles, soil water content and the electrical conductivity of the pore fluid. The amount of the free ions present in the pore fluid establishes the thickness of the double layer, the value of the zeta potential and of the electro-osmotic permeability of the soil. The zeta potential of the soil depends on the salinity of the pore fluid and on the $\mathrm{pH}$. If the salinity of soil or pore fluid increases, the zeta potential reduces, and as a result, the electro-osmotic permeability (eq. 3) reduces leading to a reduction in the electro-osmotic flow.

In literature, many authors have studied the effectiveness of the EK treatment as concerning the dewatering of clayey soils ([3-9]), verifying, mainly at the laboratory scale, that it is strongly linked to the mineralogical nature of the soil, the applied potential, the type of electrodes placed into the soil, and the chemical composition of the interstitial fluid ([10-14]).

Some authors have analysed the effect of the EK treatment in terms of mechanical properties of treated soils ([5], [7], [9]). Indeed, it is well known that all the electrochemical processes induced by the application of an electric field into a soil volume induce a significant irreversible change in the physico-chemical and mechanical properties of the treated soil ([15]). These changes must necessarily be analysed in detail in order to verify the engineering applicability of this treatment at the real scale.

Starting from the experimental evidences of previous works ([1], [5], [6]), a multidisciplinary research activity was developed at the University of Napoli Federico II to analyse in detail the role of some factors in the effectiveness of EK treatment in different soils.

\section{Experimental program}

The experimental activity has been carried out on two different soils; the first coming from Bologna, north Italy and the second coming from Napoli, south Italy. The last one comes from an ongoing dredging activity in the commercial port of Napoli.

The mineralogical composition of each soil sample was evaluated by XRD analysis on a powder sample using a
Panalytical X'Pert Pro diffractometer equipped with PixCel 1D detector (operative conditions: $\mathrm{CuK} \alpha_{1} / \mathrm{K} \alpha_{2}$ radiation, $40 \mathrm{kV}, 40 \mathrm{~mA}, 2 \Theta$ range from 5 to $80^{\circ}$, step size $0.0131^{\circ} 2 \Theta$, counting time 40 s per step).

The XRD spectra in Figure 1 showed that the main crystalline phases present in the Bologna soil before the treatment are quartz $(\mathrm{Q})$, vermiculite $(\mathrm{V})$ and calcite $(\mathrm{C})$ with traces of halloysite $(\mathrm{H})$. As reported by Lirer et al, ([16]) the soil coming from Napoli has constituted by analcime, calcite, quartz, halite with presence of clay phases.

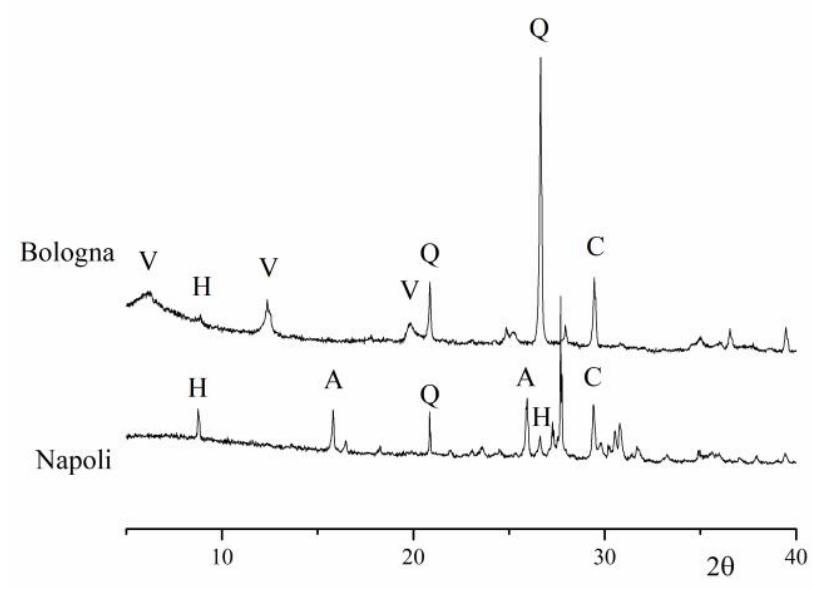

Fig. 1. Mineralogical composition of the two soils.

The grain size distributions and the soil properties are reported in Figure 2. The tested soils can be identified as low (Napoli, PI=0.046) and high (Bologna, PI=0.36) plasticity soils.

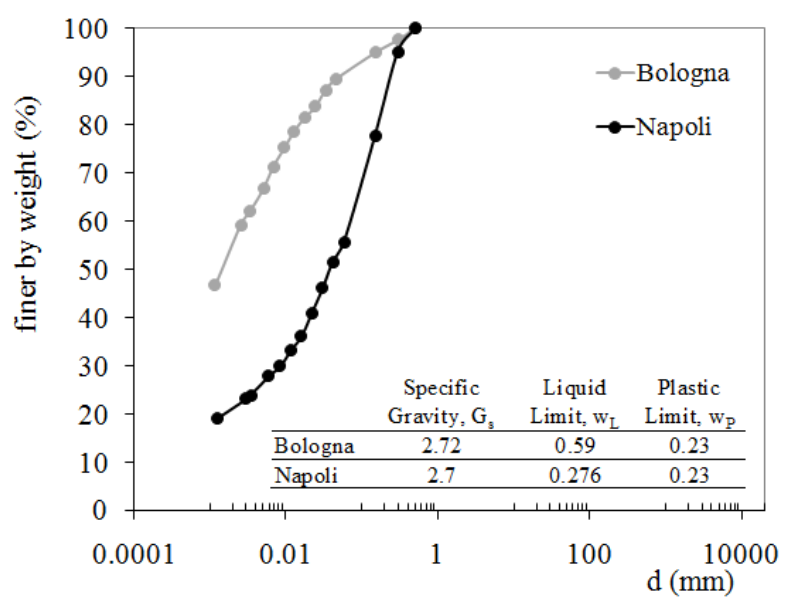

Fig. 2. Grain size distribution and physical properties of the tested soils.

All the laboratory tests have been carried out on remoulded specimens, obtained by drying the soil in stove at $105^{\circ} \mathrm{C}$ and then mixing it with tap water or sea water to obtain a sludge with an initial water content $\mathrm{w} \sim 1.4 \mathrm{w}_{\mathrm{L}}$ (with $\mathrm{w}_{\mathrm{L}}$ the liquid limit).

The experimental programme was planned with the aim to investigate the change in the physico-chemical and mechanical properties of the soils after the electrokinetic treatment. 


\section{Electro-kinetic test in the special oedometer}

The electrosmotic tests have been carried out in a floating special oedometer ([1], [5], [6]) designed to allow large displacements (maximum specimen height $\mathrm{H}$ $=20 \mathrm{~cm}$, internal diameter $\mathrm{D}=5 \mathrm{~cm}$ ) as expected for very soft soils. The device (Fig. 3) is capable to apply to the soil different combinations of mechanical (M) and electrical loads (EK). In the apparatus two conductive porous stones are placed at the top and the bottom base of the specimen: in the electrosmotic tests, the upper (anode) and the lower (cathode) end plates are connected to a (DC) power supply, operating under constant voltage $(\Delta \Phi)$.

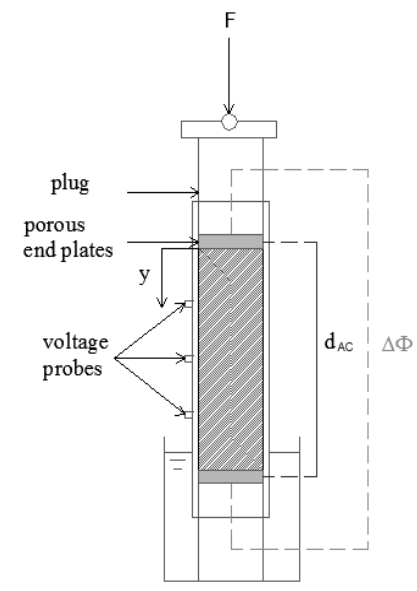

(a)

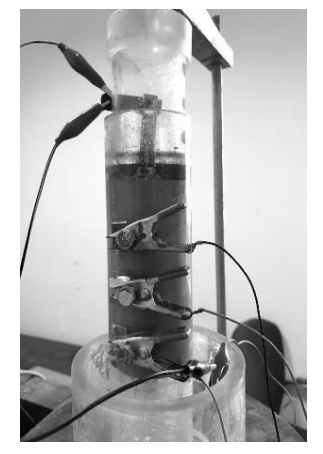

(b)
Fig. 3. Experimental device (a) scheme (b) picture.

All the tests (Tab. 1) have been carried out under the double-way drainage conditions, because the drainage is allowed at both sides of the specimen (cathode and anode side).

Two reference tests (named SE-M1, SE-M5) have been carried out applying the mechanical load, without the application of the electrical field.

Six electrokinetic (EK) tests have been performed on both soils under different test conditions (applied voltage and pore fluid). The influence of the pore fluid has been evaluated using, in the preparation of the reconstituted specimens, tap water and seawater. In the electrokinetic tests, the voltage has been applied together with a low mechanical vertical loading $\left(\sigma^{\prime}{ }_{\mathrm{v}}=1 \mathrm{kPa}\right)$, therefore the water flow in these tests has been induced simultaneously by electrokinetic and hydraulic gradients.

\section{Fall cone tests}

For each specimen, after the test in the special oedometer (M or EK type), a fall cone test was performed on different parts of the specimens extruded from the device.

The fall cone test is a simple testing method in which a cone penetrates a soil specimen by its self-weight and the penetration depth is measured. This test is extensively used for measuring the liquid limit $\left(\mathrm{w}_{\mathrm{L}}\right)$ and the undrained shear strength $\left(\mathrm{s}_{\mathrm{u}}\right)$ of soils.
For the measurement of $\mathrm{w}_{\mathrm{L}}$, the mass and the conical angle of the cone are $60 \mathrm{~g}$ and $60^{\circ}$ respectively (JGS 0142-2009).

After the tip of the cone touches the specimens surface the cone is freely dropped; after five second the penetration is measured and the $s_{u}$ is calculated via the following equation ([17], [18]):

$$
s_{u}=k \cdot\left(W / d^{2}\right)
$$

where $\mathrm{k}$ is a constant linked to the cone angles $(\mathrm{k}$ is 0.3 for a cone angle of $\left.60^{\circ}\right), \mathrm{d}$ is the penetration depth ( $\mathrm{mm}$ ) and $\mathrm{W}$ is the weight of the cone $(60 \mathrm{~g})$.

The soil samples to test with the fall cone have been obtained by specimens extruded from the special oedometer device. The samples have been retrieved near the anode or the cathode to verify the homogeneity of the treatment, in terms of induced improvement of mechanical properties.

Table 1. Tests carried out in the special oedometer on both soils (Bologna and Napoli).

\begin{tabular}{lccc}
\hline TEST & $\begin{array}{c}\text { Vertical load } \\
\sigma_{\mathrm{v}}^{\prime}(\mathrm{kPa})\end{array}$ & $\begin{array}{c}\text { Applied voltage } \\
\Delta \phi(\mathrm{V})\end{array}$ & $\begin{array}{c}\text { Pore } \\
\text { fluid }\end{array}$ \\
\hline SE-M1 & & 0 & \\
SE-EK2 & 1 & 6 & Tap \\
SE-EK3 & & 12 & water \\
SE-EK4 & & 20 & \\
\hline SE-M5 & & 0 & \\
SE-EK6 & 1 & 6 & Sea \\
SE-EK7 & & 12 & water \\
SE-EK8 & & 20 & \\
\hline
\end{tabular}

\section{Experimental results}

\subsection{Tests in the special oedometer}

The results obtained in the special oedometer (Fig. 4) show that the two tested soils have a different behaviour during the application of the current field.

In the test carried out on Bologna specimens (Fig. 4a) with tap water, the electric field induces larger settlement (SE-EK3) and is effective in speeding up the dewatering process in comparison with the test carried out without the applied voltage (SE-M1). In the case of the test on the specimen prepared with the seawater (SEEK7), the effect of the electric field is completely different. The soil settlement is smaller than the one measured in the test with only the mechanical load (SE$\mathrm{M} 1)$ : in this case the current field is ineffective for the dewatering process, inducing a lower water flow.

In the tests carried out on Napoli specimens (Fig. 4b), the application of the electrical field (SE-EK3 and SEEK7) induces displacements slightly smaller than the case with the mechanical load alone (SE-M1). For this soil, the electrical field is ineffective for the dewatering process regardless of the adopted pore fluid

This result is somewhat unexpected and needs further study to explain the reasons. 
During the electrosmotic consolidation process, the current intensity (i) has been calculated via the Ohm's law. In Figure 5, the value of the current intensity in the tests performed on Bologna specimens are plotted. It can be noted that, for all the tests, the values of $i$ are higher at the beginning of the tests, and then decrease in time because of the reduction of ionic species in the pore water induced by the electro-migration and electroosmotic flow. As expected, in the tests with seawater (SE-EK7, SE-EK8), the values of the current intensity are higher. This is due to the electrical conductivity of the used pore fluid: the electrical conductivity of the tap water is in the range of 0.005 to $0.05 \mathrm{~S} / \mathrm{m}$ compared with $5 \mathrm{~S} / \mathrm{m}$ for the seawater.

The current reaches its maximum value shortly after the electro-dewatering process has started and then steadily decreases. This is the result of two opposing effects. As water is removed, the height of the sample decreases and this decreases the electrical resistance of the soil. At the same time, as water is removed, the percent of solids increases, thus increasing the electrical resistance. Finally, the electrical resistance of the soil formed is too high and the electrical current reduces and eventually ceases, electro-dewatering stops, and no more water is removed.

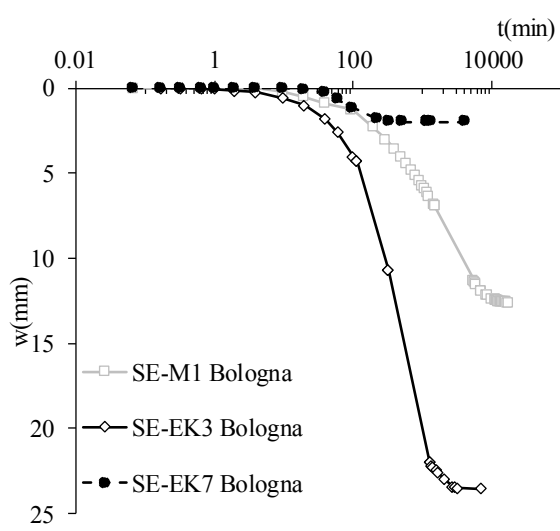

(a)

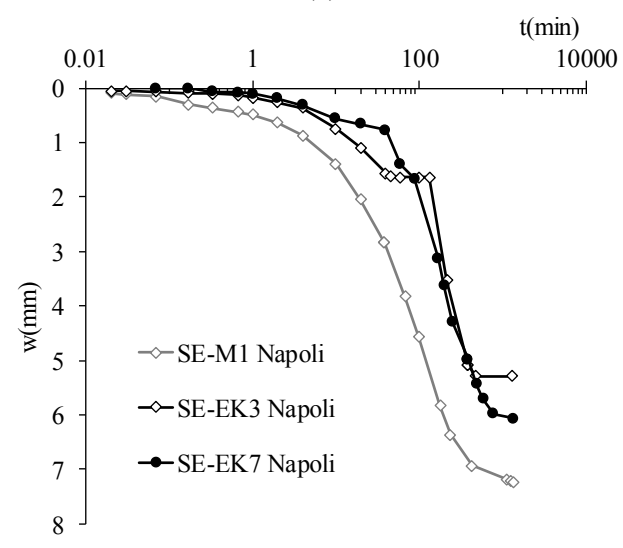

(b)

Fig. 4. Soil settlement versus time (a) Bologna (b) Napoli

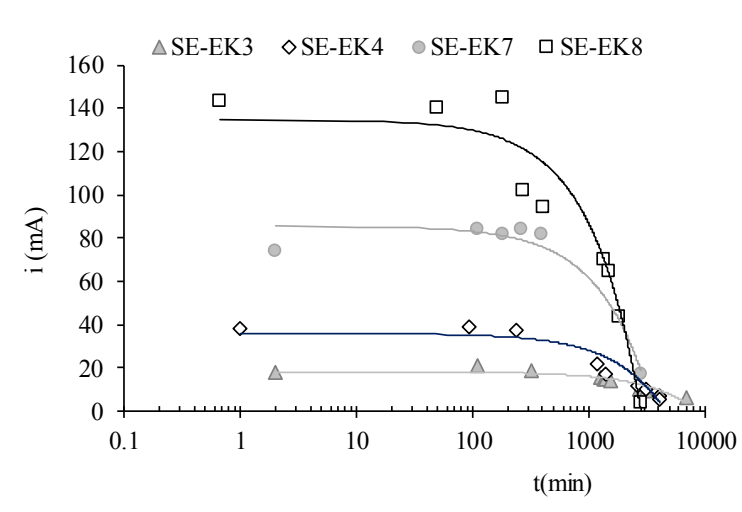

Fig. 5. Current intensity during the EK tests on the Bologna soil.

\subsection{Fall cone tests}

Soil specimens have been extruded at the end of the EK tests, divided in two parts (anode and cathode side) and fall cone tests have been performed on both samples.

The fall cone test has been chosen to have a quick estimation of the effect of electro-kinetic treatment on the mechanical properties of the soil.

The undrained shear strength $\left(\mathrm{s}_{\mathrm{u}}\right)$ has been calculated via the eq (4) and plotted versus the water content (w) in Figure 6 for the two soils. It is evident that, for both soils, all the EK treated specimens exhibit higher undrained shear strength after the treatment, with values of $s_{u}$ (lower bound curve, Fig. 6) well above the ones pertaining at the same condition (water content) of the un-treated specimens (test SE-M1, Fig. 6).

The role of the porosity fluid is not clearly recognizable from the results plotted in Figure 6: only for the Bologna soil (Fig. 6a), it seems that the sea water effect is more effective in the improvement of shear strength at the cathode side. Other tests are under course to clarify such aspect.

From a qualitative point of view, it could be stated that the observed increase in the soil mechanical strength is due to a chemical modification induced by the electrosmotic process.

In order to verify if the treatment induces an irreversible change in the plasticity index PI of the tested soils, the fall cone has also been used to determine the liquid limit of some soil samples after the electrosmotic tests.

In Table 2, some results are reported for the Bologna soil in terms of the percentage increase of the liquid limit respect to the natural one $\left(\mathrm{w}_{\mathrm{L}}=0.59\right)$.

In almost all the tests (Tab. 2), an increasing of the liquid limit has been measured. According to other similar results ([19-22]) the liquid limit of the soil near the anode side is always lower than soil around the cathode, for both the adopted pore fluids.

The percentage increase in $\mathrm{w}_{\mathrm{L}}$ ranges from a maximum of $36.1 \%$ for the cathode side in the test with seawater (SE-EK8 test) to a minimum of $0.6 \%$ for the anode side in the test with tap water (SE-EK3 test).

The rationale behind these contradictory observations could be attributed to various factors such as soil type, change in the fabric orientation, exchangeable ions, 
mixing of anode material with clay, change in salt concentration and $\mathrm{pH}$ of the clay.

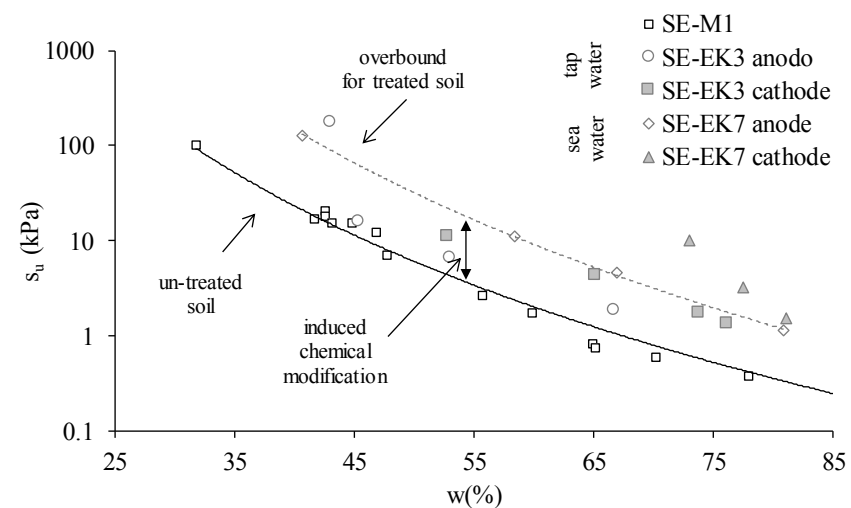

(a)

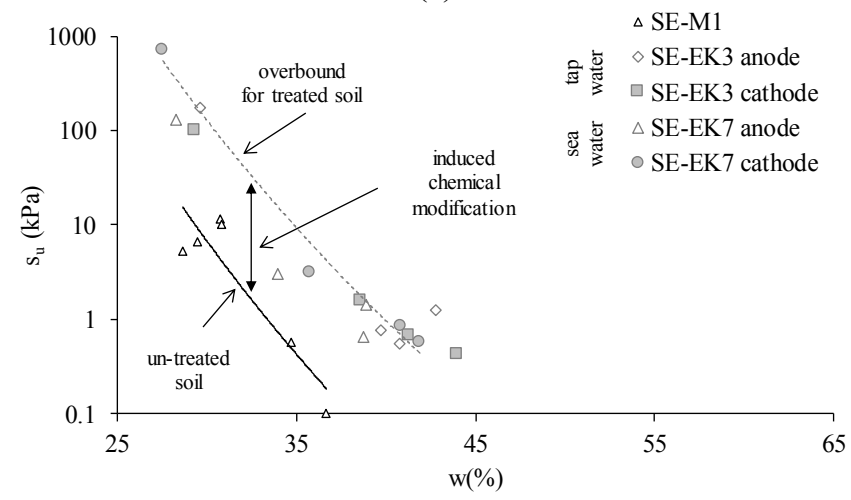

(b)

Fig. 6. Values of undrained shear strength $(\mathrm{Su})$ of treated soils obtained via the fall cone tests results: (a) Bologna (b) Napoli soils.

Table 2. Measurements of liquid limit at the end of the EK3, EK4, EK7 and EK8 tests on the Bologna soil.

\begin{tabular}{lcc}
\hline \multirow{2}{*}{ TEST } & \multicolumn{2}{c}{$\Delta \mathrm{wL}_{\mathrm{w}} / \mathrm{wL}(\%)$} \\
& anode & cathode \\
\hline SE-EK3 & 0.6 & 9.8 \\
SE-EK4 & 0.8 & 19.5 \\
SE-EK7 & 25.5 & 34.9 \\
SE-EK8 & 1.1 & 36.1 \\
\hline
\end{tabular}

\subsection{Chemical and morphological characterization}

After the EK treatment the Bologna soil presented the same crystalline phases, even if a partial dissolution of the clayey phases can be revealed at low angles (see Fig. 7).

The microstructure of the soil samples was also examined by scanning electron microscopy SEM (SEM, Cambridge S440). Inspecting the SEM images for the Napoli soil before and after the EK treatment (Fig. 8) it is possible to notice a more disordered microstructure, in accordance with other similar tests reported by Yuanzhao and Zhenxia ([23]).

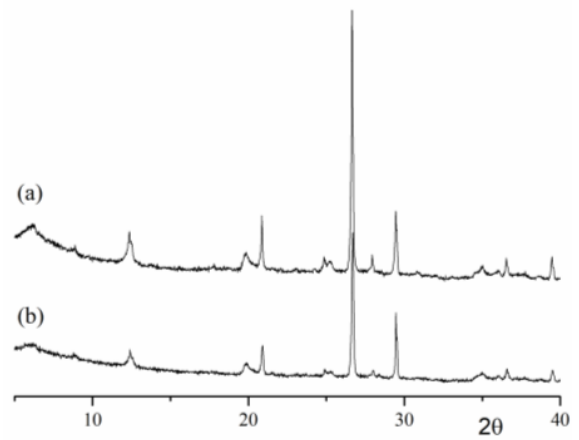

Fig. 7. XRD spectra of Bologna soil (a) before and (b) after EK treatment.

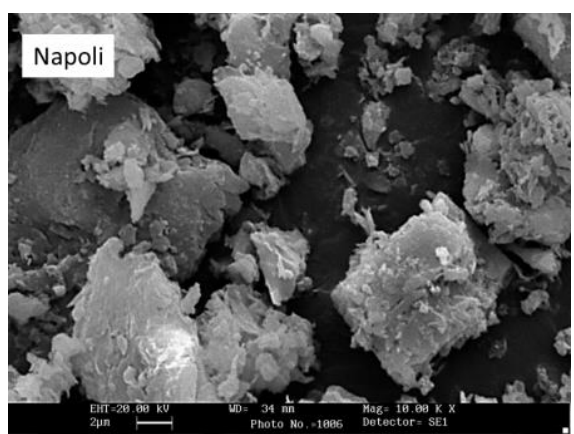

(a)

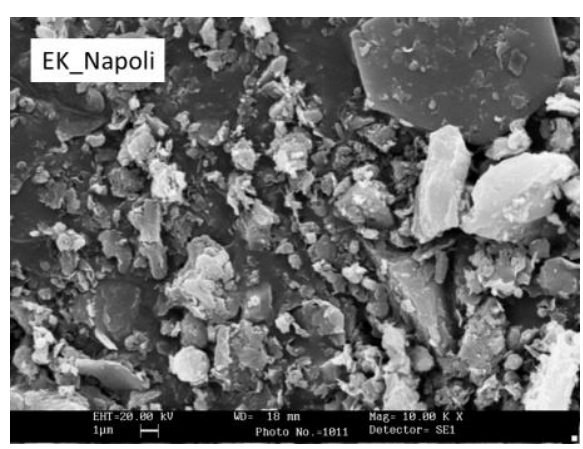

(b)

Fig. 8. Microstructure of the Napoli soil before (a) and after (b) the EK treatment.

\section{Conclusions}

In this paper, an experimental research on the electroosmotic consolidation in two different soils was conducted and the impacts of the pore fluid were observed. The main conclusions were drawn as follow:

- The electro-osmotic process accelerates the water discharge from the Bologna material with tap water, while the effect on both materials remoulded with seawater isn't the same.

- The current intensity becomes smaller as the electroosmosis goes ahead. It is caused mainly by the increasing resistance in the soil.

- The soil demonstrates higher shear strength without significant decreases in water content.

- The material changes after the electro-osmotic process, showing a more disordered microstructure. 


\section{References}

1. A. Flora, S. Gargano, S. Lirer, L. Mele, Geotech Geol Eng, 35(6): 2879-2890. (2017)

2. J.K. Mitchell and K. Soga, Fundamentals of soil behaviour (3rd edition. New York, USA: John Wiley, 2005)

3. L. Bjerrum, J. Moum, and O. Eide, GEOTECHNIQUE, 17: 214-235. (1967)

4. L. Casagrande, Proceedings, 2nd International Conference on Soil Mechanics and Foundation Engineering, Rotterdam, 1: 218-223. (1948)

5. A. Flora, S. Gargano, S. Lirer, L. Mele, Procedia Eng, 158: $3-8$. (2016)

6. S. Gargano, S. Lirer, A. Flora, Proc. Inst. Civ. Eng. Ground Improv, DOI: 10.1680/jgrim.18.00010. (2018)

7. K.Y. Lo, K.S. Ho, and I.I. Inculet, CAN GEOTECH J, 28: 62-73. (1991)

8. N.C. Lockhart, Colloids Surf, 6: 253-269. (1983)

9. K.R. Reddy, A. Urbanek, and A.P. Khodadoust, J Environ Manage, 78: 200-208. (2006)

10. G. H. Bolt and R. D. Miller, Proc. Am. Soc. Soil Sci., 19: 285-288. (1955)

11. G. Mesri and R.E. Olson, GEOTECHNIQUE, 20(3): 261270. (1970)

12. R. Moore, GEOTECHNIQUE, 41(1): 35-47. (1991)

13. A. Sridharan and G. Ventakappa Rao, GEOTECHNIQUE, 23 (3): 359:382. (1973)

14. A. Sridharan, Indian Geotech. J., 21(1): 1-136. (1991)

15. J.K. Mitchell, Fundamentals of soil behaviour (2nd ed. New York, USA: John Wiley and Sons, 1993)

16. S. Lirer, B. Liguori, I. Capasso, A. Flora and D. Caputo, J Environ Manage, 191: 1-7. (2017)

17. S. Hansbo, Proc. Roy. SGI, 14: 7-48. (1957)

18. D. Wood and C.P. Wroth, Ground Engng, 11(3): 37. (1978)

19. D.V. Morris, S.F. Hillis and J.A. Caldwell, CAN GEOTECH J, 22(1):17-24. (1985)

20. A. Rittirong, R.S. Douglas, J.Q. Shang and E.C. Lee, GEOSYNTH INT, 15(5):369-381. (2008)

21. B. Win, V. Choa and X. Q. Zeng, SOILS FOUND, 41(5):15-23. (2001)

22. H. Wu, L. Hu and G. Zhang, J MATER CIVIL ENG, 28(8):6016010. (2016)

23. C. Yuanzhao and L. Zhenxia, EJGE, 21(19): 6571-6582. (2016)

\footnotetext{
* Corresponding author: sara.gargano@unina.it
} 